\title{
Mass Media Exposure and use of family planning in Ethiopia: Evidence from EDHS 2016
}

Habtamu Alganeh ( $\nabla$ habtamu.alganeh@yahoo.com )

University of Gondar College of Medicine and Health Sciences

\section{Berhanu Fikade Endehabtu}

University of Gondar

Research article

Keywords: Contraceptive, Family planning, Ethiopia, Mass media, Utilization

Posted Date: August 31st, 2019

DOI: https://doi.org/10.21203/rs.2.13811/v1

License: (9) This work is licensed under a Creative Commons Attribution 4.0 International License. Read Full License 


\section{Abstract}

Background Mass media is a significant force in the digital divide era in which communities and individuals are engaged constantly with messages from a crowd of information sources. As family planning is influenced by mass media, there is a need to study the impact of mass media exposure on family planning utilization.

\section{Background}

Family planning use is crucial to improving women's reproductive and sexual health. Despite increasing activities of family planning programs within Africa, the utilization in the region has remained low.

Family planning(FP) reduces the risks of maternal and newborn deaths and gives to the general health of communities and countries by lessening unsustainable population growth and poverty rates(1-3).

Utilization of mass media to make populations aware of the benefits of the use of family planning is one of the strategy to promote family planning. With their broad reach and powerful influence, mass media can help to improve reproductive health practices(4).

The uptake of family planning still remains low in Sub-Saharan Africa(5), resulting high rates of unplanned pregnancy, unwanted pregnancy and unsafe abortion which mainly lead to high maternal morbidity and mortality(6).

Evidence reveled that irrespective of goals of family planning interventions like communication can have a positive influence on people's attitude, lead to behavioral change and increase knowledge(7).

Different factors linked with nonuse of family planning services like lack of awareness and misconceptions for the services(8).

Mass media as reliable sources of information have the ability for the promotion of consciousness, increase awareness level, and influence attitudes towards family planning $(9,10)$.

Mass media has an important role for family planning programs, which provide services to reduce the number of unwanted pregnancies, to improve the health of women and children by spacing birth and reduce the risk of sexually transmitted infections $(5,11-13)$.

Finding from Kenya showed that access to media messages affected ever use of contraceptives, current use, intention to use contraceptives and desire for future births(14).

In addition, several studies have focused on how mass media campaigns on family planning have led to improvement in reproductive health in different countries.

Channels should be used to ensure that coordinated behavioral change communication messages reach the desired population. Choice of the channel for the activities should be based on target audience and local availability(11).

Literature from developing countries showed that women who watch Television (TV) are more likely to utilize family planning methods when compared to women who do not watch TV at all(15).

Studies suggest that women who had exposure to radio and Television had an information towards family planning services when compared with women who do not have 
exposure(16-18).

This study, therefore, is aimed to assess the impact of mass media on family planning by reviewing the Ethiopian Demographic and Health Survey (EDHS) 2016. The finding will provide a vital clue into the vast opportunity inherent in the use and engagement of the mass media to improve contraceptive utilization among Ethiopian women.

\section{Materials And Methods}

\section{Study design and setting}

A survey-based study was designed using the EDHS datasets of the year 2016. The survey were conducted in January to June, 2016. Ethiopia, officially known as the Federal Democratic Republic of Ethiopia, is located in the horn of Africa. Ethiopia is the most populous landlocked country in the world and the second most populated nation on the African continent, with over 100 million inhabitants (2017 estimates)(19). It occupies a total area of 1,104,300 km2 and has Addis Ababa as its capital city.

\section{Data collection}

The 2016 EDHS data set was downloaded from MEASURE DHS (Demographic and Health Survey) website after obtaining the necessary permissions for their download and further analyses. http://www.dhsprogram.com.

\section{Sampling procedure}

Ethiopia demography and health survey is multistage stratified that used two-stage probability samples which were stratified by geographic region and by urban/rural areas within each region that entirely covers the targets population of Ethiopia. In the first stage of selection, the primary sampling units (PSUs) are selected with probability proportional to size (PPS) within each stratum. The PSU forms the survey cluster a total of 645 EAs (202 EAs in urban areas and 443 EAs in rural areas). Then fixed number of 28 households (25-30) per cluster were selected with an equal probability systematic selection from the newly created household listing in the second stage of survey. The overall probability of selection of a household will differ from cluster to cluster(20).

\section{Statistical Analysis}

Data analysis was done using SPSS software, version 20 after data cleaning and recoding. Descriptive statistics were done to determine the frequencies of sociodemographic and media exposure of the respondents. This was then followed by bivariate logistic regression at the second-level analysis to study the effect of media exposure on use of contraceptives. Significance at bivariate logistic regression was set at $\mathrm{P}<0.05$ at $95 \%$ confidence interval (CI). The media exposure variables that were found to be significant at bivariate logistic regression were then introduced into the multiple logistic regression models that included the confounding variables to study the true and independent influence of the media variables on contraceptive use among the women. $\mathrm{P}<0.05$ at $95 \%$ CI was taken as significant. The results are presented in odds ratios (ORs) with 95\% CIs. 
The total number of women studied was 15,683. One fifth of the respondents were in age group of 15-19 age group. Majority (77.8\%) of the women resided in rural areas. Nearly half $(47.8 \%)$ of the women had no education. The summary of the sociodemographic is presented in (Table 1).

Table 1:- Sociodemographic characteristics of women in EDHS 2016

\begin{tabular}{|c|c|c|}
\hline Variable & Frequency & Percent \\
\hline \multicolumn{3}{|l|}{ Age Group } \\
\hline $15-19$ & 3381 & 21.6 \\
\hline $20-24$ & 2762 & 17.6 \\
\hline $25-29$ & 2957 & 18.9 \\
\hline $30-34$ & 2345 & 15.0 \\
\hline $35-39$ & 1932 & 12.3 \\
\hline $40-44$ & 1290 & 8.2 \\
\hline $45-49$ & 1017 & 6.5 \\
\hline \multicolumn{3}{|l|}{ Marital status } \\
\hline Married & 10014 & 63.9 \\
\hline Living with partner & 209 & 1.3 \\
\hline Widowed & 429 & 2.7 \\
\hline Divorced & 764 & 4.9 \\
\hline Separated & 230 & 1.5 \\
\hline Never in union & 4036 & 25.7 \\
\hline \multicolumn{3}{|l|}{ Region } \\
\hline Tigray & 1129 & 7.2 \\
\hline Afar & 128 & 0.8 \\
\hline Amhara & 3714 & 23.7 \\
\hline Oromia & 5701 & 36.4 \\
\hline Somali & 459 & 2.9 \\
\hline Benishangul & 160 & 1.0 \\
\hline SNNPR & 3288 & 21.0 \\
\hline Gambela & 44 & 0.3 \\
\hline Harari & 38 & 0.2 \\
\hline Addis Ababa & 930 & 5.9 \\
\hline Dire Dawa & 90 & 0.6 \\
\hline \multicolumn{3}{|l|}{ Residence } \\
\hline Urban & 3476 & 22.2 \\
\hline Rural & 12207 & 77.8 \\
\hline \multicolumn{3}{|l|}{ Education } \\
\hline No education & 7498 & 47.8 \\
\hline Primary & 5490 & 35.0 \\
\hline Secondary & 1817 & 11.6 \\
\hline Higher & 877 & 5.6 \\
\hline
\end{tabular}

This study showed that current contraceptive use among the respondents was 25.3\%, comprising mainly one fourth of the respondents' use of modern methods and $0.5 \%$ traditional methods (Table 2). 
Table 2; Current use of contraceptives among the respondents by method type

\begin{tabular}{lll}
\hline Variable & Frequency & Percentage \\
\hline Current use by method type & & \\
No method & 11709 & 74.7 \\
\hline Traditional & 75 & 0.5 \\
\hline Modern & 3899 & 24.9 \\
\hline
\end{tabular}

Majority (86.4\%) of the women did not read newspapers/magazine, One six of them (16.7\%) reported listening to radio less than once a week; Two thousand four hundred eighty five (15.8\%) of them watched television at least once a week. The summary of exposure of women to mass media is presented in (Table 3)

Table 3: Exposure of women to mass media in EDHS 2016

\begin{tabular}{|c|c|c|}
\hline Variable & Frequency & Percent \\
\hline \multicolumn{3}{|l|}{ Ownership } \\
\hline Radio & 4781 & 30.5 \\
\hline TV & 2581 & 16.5 \\
\hline \multicolumn{3}{|c|}{ Frequency of reading newspaper/ magazine } \\
\hline Not at all & 13548 & 86.4 \\
\hline Less than once a week & 1517 & 9.7 \\
\hline At least once a week & 619 & 3.9 \\
\hline \multicolumn{3}{|l|}{ Frequency of listening to radio } \\
\hline Not at all & 10485 & 66.9 \\
\hline Less than once a week & 2617 & 16.7 \\
\hline At least once a week & 2581 & 16.5 \\
\hline \multicolumn{3}{|l|}{ Frequency of watching television } \\
\hline Not at all & 11295 & 72.0 \\
\hline Less than once a week & 1904 & 12.1 \\
\hline At least once a week & 2485 & 15.8 \\
\hline \multicolumn{3}{|l|}{ Mobile telephone ownership } \\
\hline Yes & 4283 & 27.3 \\
\hline No & 11400 & 72.7 \\
\hline \multicolumn{3}{|l|}{ Use of internet } \\
\hline Never & 14904 & 95.0 \\
\hline Yes, last 12 months & 693 & 4.4 \\
\hline Yes, before last 12 months & 86 & 0.6 \\
\hline
\end{tabular}

On bivariate analysis reading newspapers for at least once a week, listening to radio for at least once a week and watching television for at least once a week were positively associated with family planning utilization.

Multivariable analysis showed that the use of contraceptives was significantly associated with reading newspapers for less than once a week (AOR $=1.44 ; 95 \%$ CI $=1.139-1.832$ ), 
listening to radio for at least once a week (AOR $=1.40 ; 95 \% \mathrm{CI}=1.248-1.570)$, and using internet in the last 12 months (AOR $=2.36 ; 95 \%$ CI $=1.292-4.340$ ). There was an improvement in odds for contraceptive use with increase in the three media variables when media exposure increased to at least once a week (Table 3).

Table 3:- Multivariable analysis for media influence on the current use of contraceptives among the women 


\section{Media exposure variables and possible confounding Current use of contraceptives variables \\ Adjusted $\mathrm{P} \quad 95 \% \mathrm{CI}$ \\ OR}

Frequency of reading newspapers

Not at all

Less than once a week

$1 \quad 0.007$

$\begin{array}{lll}1.444 & .002 & 1.139\end{array}$

1.832

At least once a week

1.279

$.057 \quad .993$

1.648

Frequency of Listening to radio

Not at all

Less than once a week

At least once a week

Frequency of Watching TV

Not at all

Less than once a week

At least once a week

Use of internet

Never

Yes, last 12 months

Yes, before last 12 months

Age Group

15-19

20-24

25-29

30-34

35-39

$40-44$

$45-49$

Residence

Rural

Urban
1

$\begin{array}{lll}1.096 & .113 & .979\end{array}$

1.227

$1.400 \quad .000 \quad 1.248-$

1.570

$\begin{array}{llll}1 & .305 & & \\ 1.079 & .246 & .949 & - \\ & & 1.228 & \\ 1.113 & .176 & .953 & - \\ & & 1.300 & \end{array}$

$\begin{array}{llll}1 & .000 & & \\ 2.368 & .005 & 1.292 & - \\ & & 4.340 & \\ 1.416 & .285 & .749 & - \\ & & 2.680 & \\ & & \end{array}$

1

$\begin{array}{lll}.414 & .000 & .332-.515\end{array}$

$\begin{array}{llll}1.889 & .000 & 1.557 & -\end{array}$

2.292

$\begin{array}{lll}2.882 & .000 \quad 2.395\end{array}$

3.469

$\begin{array}{lll}2.827 & .000 \quad 2.343\end{array}$

3.410

$\begin{array}{lll}2.242 & .000 & 1.847\end{array}$

2.721

$\begin{array}{lll}2.056 \quad .000 & 1.671\end{array}$

2.530

CI: Confidence interval, OR: Odds ratio

\section{Discussion}


This study found that access to mass media messages increased the possibility of women making use of family planning. This means that access to information on family planning is effective in positively influencing peoples' attitude towards use of family planning in Ethiopia and this results supports earlier findings by other researchers who posited that mass media messages on family planning was effective in increasing the use of family planning(18).

This study on impact of mass media on the current use of contraceptives among Ethiopian women found a significant positive influence of mass media on the current use of contraceptives, even after controlling for the possible confounding sociodemographic variables. Women who were exposed to the four main media platforms for even less than once a week were more likely to be using contraceptive commodities than their counterparts who were not exposed at all.

Radio messages have the greatest impact on the propensity for people to use family planning, and it is followed in importance by newspaper messages. This finding is in agreement with other studies in which they note that radio and newspaper exposure have positive impact on family planning service utilization $(12,17,18)$.

There is high odds of ratio between use of internet and family planning program utilization, this means women who had access to internet for in the last 12 months were 2.36 times more likely to use family planning program when compared to with counter parts.

Another significant association was depicted between type of residence and family planning program, women who live in urban areas of the country use 1.31 times more likely family planning programs when compared to women who live in rural areas of the country. This finding is supported by earlier studies(13).

This study revealed that significant and positive odds of ratio between use of family planning programs and respondents age group in accordance with reference category of the 15-19 age group. This is in line with other studies, increase in age groups significantly increase the likelihood of family planning program utilization $(17,21)$.

\section{Conclusions}

Mass media has a key role in improving contraceptive use among Ethiopian women`s. In this study mass media has positive influence on family planning utilization.

\section{Declarations}

\section{AUTHORS' CONTRIBUTIONS}

All authors contributed equally in the proposal development. All authors were involved in data analysis. HAG and BFE prepared the manuscript and revised the paper. All authors have read and approved the final manuscript. 


\section{ACKNOWLEDGEMENTS}

The authors would like to thank Measure DHS Corporation for providing the datasets for this study.

\section{CONFLICT OF INTEREST}

Authors have declared that no competing interests exist.

\section{Funding}

No funding was accepted

\section{Data availability}

The dataset(s) supporting the conclusions of this articles (are) available in the Demographic and Health Survey repository, in https://dhsprogram.com/data/dataset_admin/index.cfm_2016

\section{Ethical clearance}

The data accessed by registration on the DHS website (www.dhsprogram.com ) since it is secondary data after full authorize and approval from the DHS committee the database was used. Prior to the actual interview informed consent was obtained from the participants, their guardian or household heads. Data was used only for the purpose of statistical reporting and analysis, and only for the proposed research entitled with impact of mass media exposure towards family planning use in Ethiopia. The data treated as confidential, and no effort should be made to identify any household or individual respondent interviewed in the survey.

\section{Abbreviations}

AOR; Adjusted odds ratio

CI; Confidence interval

DHS; Demographic and Health survey

EA; Enumeration area

EDHS; Ethiopian demographic and Health survey

FP; Family Planning

OR; Odds ratio 
PPS; Probability proportional to size

PSUs; Primary sampling units

SPSS; Statistical Package for social science

TV; Television

\section{References}

1. Canning D, Schultz TP. Family Planning 4 The economic consequences of reproductive health and family planning. Lancet [Internet]. 2012;380(9837):165-71. Available from: http://dx.doi.org/10.1016/S0140-6736(12)60827-7

2. Cleland J, Bernstein S, Ezeh A, Faundes A, Glasier A, Innis J. Sexual and Reproductive Health 3 Family planning : the unfi nished agenda. 2006;368.

3. Omoera OS. Broadcast Media in Family Planning Matters in Rural Nigeria : The Ebelle Scenario. 2015;1(2):77-85.

4. Peters J, Strupat C, Vance C. The Journal of Development Studies Television and Contraceptive Use - A Weak Signal ? 2014;(December 2015).

5. Jr WC, Karim QA, El-sadr W, Haffner DW, Kalema-zikusoka G, Rogo K, et al. Family Planning and the Millennium Development Goals. 2015;329(September 2010):1197080.

6. Gonie A, Wudneh A, Nigatu D, Dendir Z. Determinants of family planning use among married women in bale eco-region, Southeast Ethiopia : a community based study. 2018;1-10.

7. Garenne M. Education and Fertility in A Longitudinal Perspective DHS ANALYTICAL STUDIES 33. 2012;(December).

8. Access O. Factors influencing the uptake of family planning services in the Talensi District, Ghana. 2015;8688:1-9.

9. Kasa AS, Tarekegn M, Embiale N. Knowledge, attitude and practice towards family planning among reproductive age women in a resource limited settings of Northwest Ethiopia. BMC Res Notes [Internet]. 2018;7-12. Available from: https://doi.org/10.1186/s13104-018-3689-7

10. Medicine F, Sciences H. Medical Students ' Use of and Attitudes Towards Medical Applications. 2012;1(4):16-21.

11. Republic FD. NATIONAL GUIDELINE FOR FAMILY PLANNING Federal Democratic Republic of Ethiopia. 2011;

12. Kulkarni KR, Hiremath LD, Mannapur BS, Ghattargi CH, Mallapur AA. Role of Mass Media In Utilisation of Family Planning Methods. 2011;53:349-57. 
13. Worku AG, Tessema GA, Zeleke AA. Trends of Modern Contraceptive Use among Young Married Women Based on the 2000 , 2005 , and 2011 Ethiopian Demographic and Health Surveys : A Multivariate Decomposition Analysis. 2015;1-14.

14. Okigbo CC, Speizer IS, Corroon M, Gueye A. Exposure to family planning messages and modern contraceptive use among men in urban Kenya, Nigeria , and Senegal : a crosssectional study. Reprod Health [Internet]. 2015;1-11. Available from: http://dx.doi.org/10.1186/s12978-015-0056-1

15. Westoff CF, Koffman DA, Moreau C, International ICF. The Impact of Television and Radio on Reproductive Behavior and on hiv / aids kNOWLEDGE AND bEHAVIOR DHS ANALYTICAL STUDIES 24. 2011;(November).

16. Ugboaja JO, Oguejiofor CB, Oranu EO, Igwegbe AO. Assessing the Influence of Mass Media on Contraceptive Use in Nigeria : A Secondary Analysis of 2013 Nigerian National Demographic and Health Survey. 2018;39-44.

17. Ajaero CK, Odimegwu C, Ajaero ID, Nwachukwu CA. Access to mass media messages , and use of family planning in Nigeria : a spatio- demographic analysis from the 2013 DHS. BMC Public Health [Internet]. 2016;1-10. Available from: http://dx.doi.org/10.1186/s12889-016-2979-z

18. Tsehay AK, Zegeye DT, Yilma TM. Impact of Mass Media Exposure on Family Planning: Analysis of the Ethiopian Demography and Health Survey. 3(2):405-12.

19. Bank W. Ethiopian Population Estimate. 2017.

20. CSA. Ethiopia demographic and health survey 2016: Key Indicators Report .

21. Mawajdeh S. Demographic profile and predictors of unmet need for. 2007;33(1). 